\title{
Umoya: Understanding the Experiential Value of Traditional African Dance and Music for Traditional Healers
}

\author{
Nonkululeko Sheilla Sandlana \\ Department of Psychology, University of Fort Hare, Alice, Eastern Cape, South Africa \\ Email:nsandlana@ufh.ac.za
}

Doi:10.5901/mjss.2014.v5n3p541

\begin{abstract}
From time immemorial traditional African societies have been considered healthy, well integrated and maintaining an enviable degree of social control over their members. People used to gather, share ideas and sing together in an attempt to communicate with the supernatural forces, especially during times of adversity. Western therapeutic approaches do not take into cognisance the spiritual dimension in the lives of the majority of the African population; an oversight on the resourcefulness of traditional African approaches. The aim of this study was to investigate the experiential values of traditional African dance and music for traditional healers using a psychodynamic perspective to conceptualise the study. A descriptive qualitative research design was used and data collection methods included focus group discussions, in-depth interviews and participant observation. The findings revealed that traditional African dance and music offers a safe environment for the release of the unconscious energies. Vibrant music can be thought provoking, heightening the traditional healers' emotions and spirituality. Furthermore, traditional African dance and music brings the traditional healers closer to their ancestors, enhancing a sense of acceptance, commitment, forgiveness for any disobedience observed, hope, safety and self discovery. The findings brought to the fore therapeutic benefits for the dancer suggesting alternative ways of coping with their difficult life situations.
\end{abstract}

Keywords: African, dance, music, traditional, traditional healer, traditional healing

\section{Background}

The popular conventional healing methods are based on a western philosophy and as such, they do not adequately address the needs of th majority of the black population. Furthermore, South Africa is a culturally diverse country and this is quite challenging for most psychologists as this warrants a need for culture sensitive and culture specific healing methods. It brings to the forefront opportunities that have not been adequately explored.

Traditional African dance and music, intlombe and ukuxhentsa are of a type used by most Africans in diagnosing and treating certain conditions. The traditional healer, igqira, communicates directly with the ancestors in an intense healing ritual. Intlombe and ukuxhentsa traditional African healing approaches embrace the client's physical, emotional and spiritual needs. They are believed to be unique in that some traditional healers are able to perceive everyday problems, are aware of body language and bodily needs, and appreciate the importance of the deity in giving expression to spiritual aspects. In her study of indigenous healing methods and the psychology of the Xhosa people, Buhrmann (1990), focused on several aspects of the body and psyche and on the way in which these, together with the forces of nature and the cosmos, are incorporated into most African healing exercises (Buhrmann, 1990). According to Buhrmann, rhythmic exercises constitute a medium through which certain mental activities are evoked for the direction of life energy into new forms of activity, whether psychical or physical, or both. These forms may include hypnotic trance, aggression, umbilini, a fast heart beat, strange voices, and gait. The songs are symbolically meaningful, classic and can be shared by all participants.

In the case of a diviner when the dancer falls into a trance, one hears voices, has visions, and speaks in tongues. This is usually preceded by increased intensity in singing, hand clapping, drumming and dancing to produce a tense, vibrant atmosphere. This is regarded as a reunification of the sacred and the natural. It is during this time that the diviner is believed to be communicating with her/his ancestors and is able to diagnose by divination, receive information about the healing ritual and/or the treatment for her/his clients (Hammond- Tooke, 1989). According to the object relations theory, the capacity to dance may be described as a reflection of (i) an idealised image of a lost object, usually a parental love (ii) an unconscious need to be real, authentic and be a true self, this in turn giving rise to a sense of worth (iii) 
defence against unacceptable feelings of envy which motivates the dancer to excel beyond expectation (Henning, 2009).

According to Karou (2000) a healing rhythm is viewed a guided journey through universal rhythms, whether individually or in relationships. As ecstatic fun it enables individuals to connect with their inner feelings and to uniquely express each rhythm. Such dance Karou refers to as a dance of personal truth since it causes release of boundaries and allows for creative openness and self-empowerment. The healing dance activates and directs energy, develops strength and fluidity, increases concentration and creativity, enhances body image and self-confidence and the development of teamwork skills. Dance also serves to express emotions and feelings and can be a form of prayer, a ritual or be simply entertaining.

According to Buhrmann $(1981,1990)$, traditional African dance and music allows the body, mind and spirit, the conscious and the unconscious, to be expressed. Rhythmic movements give opportunity for the channelling of life energy into forms of activity, whether mental or physical. However, as explained by Vontress (1999), traditional healers use music as a basic form of therapy especially in group therapy. It heals human imbalances, enhances communication with ancestors, spirits and the Almighty and causes a balance between the visible and the invisible world. Drumming causes the human body to move with drumbeats, capturing its sensation and nature itself. Traditional dance and music provide an atmosphere that is conducive to effective spirit operation. They are symbols that are necessary for transforming stored-up energy, which seizes and possesses the individual personality (Buhrmann, 1981). Furthermore, vibrant music, drumming and hand clapping of hands induce an altered state of consciousness known as shamanic ecstasy, a reunification of the sacred and the natural (Buhrmann, 1984, 1990; Hammond-Tooke, 1989; Zoja, 2000). According to Zoja (2000)ecstacy is sometimes preceded by use of hallucinogens, like the South African iboga plant.

According to Sandlana (2002), dance and rhythmic movement are used for both diagnostic and therapeutic purposes. They promote and develop better interpersonal relationships and sharpen interpersonal communication. Gladding (1997) postulates that dance and rhythmic movement help in channelling self-expression in a meaningful way by helping the dancer to adjust to reality.

Furthermore, the conventional approaches do not speak much about the spiritual dimension in the lives of human beings. By and large, these approaches are culturally too different to offer a meaningful psychological approach towards healing (Akomalafe, nd; Nxumalo, Alaba, Harris, Chersich, \& Goudge, 2011; Shizha \& Charema, 2011; Soai, 2012; Thornton, 2009). It would be understandable if practitioners were merely ignorant of the traditional African dance and music and their therapeutic potential. However, more is at issue here, for the general dismissal of such practices is, at least in part, based on the assumption of their supposedly superstitious nature.

The focus of this study was to investigate the lived experiences of traditional African dance and music for traditional healers and its significance in shaping their behaviour and helping them deal with their unacceptable desires and feelings. The discussion will include methodology, discussion of findings and recommendations.

\section{Methodology}

The researcher visited places where traditional African dance and music were taking place, that is, traditional healing rituals. The researcher personally obtained verbal consent from the traditional healers and family members for their voluntary participation in the study. Participants were studied in their natural setting so as to obtain first hand information. She asked for permission to observe activities carried out, and to record, and even take photographs of, the proceedings. Throughout the proceedings the role of the researcher was that of both a participant and an observer.

Triangulation was done in data collection and analysis to ensure reliability and validity of the findings. Focus group discussions and in depth interviews served to discover more about the conscious, semiconscious and unconscious psychological and socio-cultural factors and processes of the traditional healers, including their initiates. This allowed openness on the part of the participants enabling the researcher to obtain the widest possible range of information. The inclusion of open-ended questions enabled the participants to give more information concerning their experiences during the activity (dancing and music) and their interpretation of their experiences.

The study included twenty-five participants who were heterogeneous in terms of religious affiliation, age, sex, occupation and educational background. These participants were selected according to their experience and knowledge; qualified traditional healers and their initiates, that is, amagqira and amathwasa or abakhwetha.

\section{Discussion and Interpretation of Findings}

In traditional healing, traditional African dance and music are conducted in private or public places; in the client's home, 
riverside, sea shore or a forest. These are performed for a number of reasons including invoking the ancestral spirits in cases of healing rituals in the healing of both the individual and the entire family.

\subsection{Initiation of a traditional healer}

Traditional healing incorporates regular sessions of traditional African dance and music as part of the treatment prescribed for the ukuthwasa, a call to becoming a traditional healer. The initiate is gradually introduced to the ancestral spirits so as to enhance communication. This process is accompanied by fear of what to expect and ignorance of how one should respond. Guidance is given throughout by senior initiates and traditional healers. For the traditional healer in charge this fear may be due to fear of failure in what is being done, since this would tarnish his reputation. Intense singing, hand clapping and drumming enhance his focus on what he/she was doing rather than on what could happen, thus reducing fear and anxiety.

Furthermore, traditional African dance and music are conducted daily and early in the morning for initiates to relate their dreams to the traditional healer in charge for analysis and interpretation. This helps the traditional healer in monitoring the training progress. In some instances, traditional African dance and music are conducted every evening when preparing for the ceremony/ritual as a way of praying for the upcoming umsebenzi.

\subsection{Traditional healing ceremonies in which African dance and music are performed}

\subsubsection{The forest ceremony: Ukuguqulwa kwezilo}

In the forest, the vibrant atmosphere produced by traditional African music caused heightened emotions. This was seen as an indication of direct communication between the forest ancestors and the affected. Participants stated that during prayers and ancestral praises they were emotional because they knew they were in the forest, exposed to danger, but God and their ancestors carried them through the night. Some thought about the difficulties of traditional healing and the long road ahead, of which the songs spoke. The traditional healer interpreted the sound made by the forest creatures as a sign of acceptance of the forest ritual. This could be associated with response to the noisy disturbance of the forest's peace.

The researcher herself also experienced heightened emotions, and various reasons were given for this, for example feelings, such as pain (since her feet were pricked by thorns the previous night), worry about what she had got herself into, anxiety as to how far things would go, given the problems already encountered, and also the love of God as they went home safely in the end. Surely to her this was not due to her introduction to the ancestors nor heightened emotions as a result of excitement, ihlombe or manipulation by the traditional healer in charge, although it could be associated with the presence of the ancestral spirits.

\subsubsection{River ceremony: Imfukamo}

At the riverside, dance and music were performed to invoke ancestral spirits. Different interpretations were given about happenings at the riverside, such as the appearance of river creatures. To the traditional healers these were signs of acceptance by river spirits. To the onlookers, these could be seen as effects of the traditional African dance and music on the natural environment, that is, sound waves causing nearby objects to vibrate, thereby startling the river creatures.

\subsection{Invoking the ancestral spirits in traditional healing ceremonies and rituals}

The traditional healers and their initiates would sing and beat drums as a way of invoking the ancestors. The traditional healer in charge would ask the initiates to sing and beat the drum. This was accompanied by hand clapping and dancing. Traditional African dance and music requires full participation of family members and their ancestors. Traditional healers became tense, galloped, appeared lighter, sang loudly with facial grimacing and groaning as if in pain. This was done to pay respect to the ancestors begging them for acceptance, forgiveness and protection against evil. The traditional healers need the guidance of their ancestors Furthermore, they were to lead the traditional healer in charge in conducting the ceremony.

Amongst the songs sung were the following:

i) Ndizakuhamba nabani kula mahlath' amnyamm, kule ntsunguzi (With whom shall I go in these black forests, 
this darkness?

Singers were verbalising their fear of what they were confronted with or what they were heading for. Metaphorically, the process was referred to as a forest since the traditional healer did not know that the next day had in store for them. The forest is the place for wild animals, some of which are dangerous, and as such, anyone who travels through it is at risk. The difficulties associated with the initiation process are referred to as exposure to this type of a place and all the risks that threaten their lives.

ii) Da 'obawo sicel' amandla, dad 'obawo sicel' iintsikelelo (Aunt; father's sister, we are asking for strength. Come aunt, we are asking for blessings).

With this song singers were pleading for strength and blessings as they were going to embark on a journey to the wilderness. Being left alone on the river bank is quite a risk and one needs to have all the strength they can get. The singers were praying for the presence of the ancestors and success. They appeared tense when thinking about what was ahead of them. The singers needed to be more focused and clapping of hands, drumming, dancing and singing more vibrantly. This is believed to enhance the descent of the ancestral spirit (ukuhla komoya). Rising of emotions would be seen through facial expression, sweating, and the manner in which they were dancing (aggressive movements) with sporadic harsh uttering or screaming. It is during this time that people are forbidden from going in and out of the room so as not to disturb the prevailing atmosphere. For example, in one of the dance and music sessions a dancing traditional healer screamed saying, "Camagwini, camagwini bant' abadala, ndibona umntu ongutata, omde, onempandla engena. Unxibe isuti emnyama nehempe emhlophe uphethe ibhayibhile uthi ucela ukuba naye angavale/wa ngaphandle kulo msebenzi; I see a tall balded male entering. He is wearing a black suite and a white shirt, carrying a bible, pleading not to be excluded from the ritual". This was a family member who had passed on a long time ago. Previously this man appeared in a dream complaining of being deserted by his family as there had not been any ritual performed for him after his death; ukukhapha or ukubuyisa.

According to Buhrmann (1990), the animated state of dance and music is believed to enhance an ecstatic phase that lifts one to a higher realm of consciousness. This state is commonly viewed as an altered state of consciousness in which the individual falls into a trance state with revelation of the unconscious; past memories stored in the unconscious. It is believed that it is during this state that the traditional healer communicates with the ancestors. After this exercise, one either feels emotionally drained or refreshed. Divination, prediction of future events, ability to capture other people's suffering or pain and problem-solving takes place (Louw \& Edward, 1999). In an attempt to make traditional dance and music more effective, there are certain factors that should be taken into consideration. These factors include seating arrangement, confession, and avoidance of pollution (ritual impurity such as umlaza) and absence of distractions.

\subsubsection{Seating arrangement}

Initially the dance and music sessions were conducted in a hut with one door and small windows. Opposite the doorway would be a place called entla, a place for ancestors. As described by Buhrmann (1981), the participants (singers and dancers) are expected to sit in three concentric circles; the first circle formed by the hut, dancers forming the second circle and family members, friends and relatives the third circle. The last circle is that of singers and hand clappers.

However, nowadays the sessions are conducted in any form of a house and the entla is established as an area opposite the doorway. There is a resemblance of mandala; concentric circles as in cases of a hut. Women are expected to sit on the right side of the house, with the eldest (wife) nearest to the doorway. Women who are daughters (iintombi) of the family sit near entla. Men sit on the left side with the eldest male family member nearest the doorway.

\subsubsection{Abstinence}

Depending on the type of ritual to be performed, family members are to abstain from eating fatty foods and milk. Besides food, they are also to abstain from sexual contact and from attending funerals before and during the course of the ritual to avoid ritual impurity (Sandlana \& Mthethwa, 2008).

\subsubsection{Dress code}

Drawing from data collected through interviews and participant observation, traditional healers emphasised the importance of a dress code in traditional healing ritual. Dancers are expected to take off their shoes to show respect for the ancestors and in some cases the biological female family members (iintombi) are to take off their head gear, 
especially before the cow is slaughtered. Wives (abafazi) should wear traditional attire as a sign of respect for the ancestors (ukuhlonipha). Men wear shorts and cover their bodies with white blankets (iingcawa).

\subsection{Psychosocial effects of traditional African dance and music; Intlombe and ukuxhentsa}

\subsubsection{From unconscious to conscious}

When the atmosphere was vibrant, singing, clapping of hands, drumming and intense dancing, some traditional healers revealed a bizarre behaviour of unknown origin, for example aggression, unusual abrupt body movements associated with anger and speaking in a different voice either than the dancers'. This was referred to as possession by foreign spirits (foreign spirits). Others felt umbilini, a fast beating heart, which according to a psychoanalytic explanation may be associated with anxiety, fear of the truth that is about to surface, exposure of which will hurt the those close to her/him. To the traditional healers, this was a sign for the presence of the ancestral spirit and a message that the traditional healer is expected to communicate.

Furthermore, the lyrics of the songs reminded the traditional healers and their initiates of past painful memories and uncertainties regarding the initiate's future. For example the first song: Ndiza'kuhamba nabani kula mahlath' amnyama; and the second one Dad' obawo sicel' amandla. These bring to the fore memories that the initiate thought she/he has forgotten. One may feel saddened and anxious during the tense atmosphere of intlombe and ukuxhentsa. In one of the sessions the initiate screamed and when asked why she screamed said,

Camagu, deda mnyama, vela kukhanya. Ndiyakhahlela kuni boTshonyane, boJola, maQoma, boGaba, Cihoshe, mama uNgidi ndinyukelwa ngumoya, camagu. Le ngoma indikhumbuza apho ndivela khona, ubunzima endidlule kubo, camagu; Wanga ophezu konke asipha amandla mna, igqira lam kunye nefemeli yam, camagu meaning; Camagu, darkness go away, let there be light. I salute you Tshonyanes, Jolas, Qomas, Gaba, Cihoshe, mother Ngidi I am evoked, camagu). This song reminds me of what I have gone through, the hardships I went through, camagu. May the Almighty give me, my traditional healer and my family strength?

Furthermore, the regalia of the traditional healer bear different meanings. Different colours in their attire may have different interpretations, especially the manner in which they are mixed. For psychologists this may be interpreted as a cry for help; for example a mixture of bright colours like scarlet red and green. For other people the colour red symbolises power.

\subsubsection{Self discovery and identity formation}

Dance and music also promote identity development. The traditional healer's performance was in accordance with group rules. Special attire enhanced the development of self, and of self- image and esteem. The dancer felt more secure in the presence of group members. According to Buhrmann (1990), self-discovery occurs through mirroring one's self in the opinion of group members, thus getting to know one's self more fully. Dance also represents an opportunity to lose one's individuality by allowing submersion in the group. Inhibitions weaken so that one feels free to engage in behaviour one would never display in other circumstances. The individual is encouraged to focus on the here and now. This promotes confidence as the traditional healer competes with others in the group. Creativity was demonstrated through their regalia, dance movements and the way the traditional healers led the singing; lyrics of the songs. The regalia also enable the traditional healer to identify with the group and show the level at which one is at. For example, a qualified traditional healer wears isidlokolo, a head gear/crown, and umthika, a skirt both made up of animal skin. Also, different colours of beads depict different things. For a traditional healer blue stands for river spirits and red for foreign spirits called amandau.

\subsubsection{Dance and music as transforming agents}

Dance and music are sometimes used repeatedly to tame an aggressive client. For example one of the initiates was difficult; aggressive refusing to dance, sing and appease his ancestors. He was forced to dance as part of the initiation process. Through repeated sessions the traditional healer managed to tame him over time. Furthermore, initiates' anxiety and fears are allayed. One becomes strengthened with increasing self confidence and joy as he/she gradually feels at ease and prepared to communicate with the supernatural. One feels empowered to help others as she/he feels in contact with his/her ancestors and able to use their wisdom in solving clients' problems. 
However, according to Monteiro and Wall (2011), the symbolic nature and meaning-making qualities of traditional African dance in combination with spiritual transformation and creation of a safe environment for expression of psychologically and socially unaccepted feelings, provides the traditional healer, the initiate and her/his family with mechanisms necessary for the maintenance of harmony between the body, mind and the ancestral spirits.

Anxiety, fear, love and aggression are expressed in the lyrics of the songs and dance. This influences the traditional healer's behaviour as it enhances commitment. One pleads for forgiveness and pledges for behavioural change in order to facilitate acceptance by the ancestral spirits and significant others within the social environment. However, as explained by Leseho and Maxwell (2010), curative properties of dance released through movement, rhythm and self expression of dance provide variations in mood and level of consciousness.

\section{Recommendations}

The study strongly recommends recognition and use of traditional African dance and music in the treatment of psychological conditions, in collaboration with the conventional healing methods. The researcher argues for a culture sensitive and culture specific therapeutic methods which will benefit the majority of the South African population. There is a need for sensitisation and training of psychologists working within African settings. If such skills are imparted hopefully they will better assist those who suffer from culture-bound conditions.

\section{Conclusion}

The study has revealed some parallels between traditional African dance and music and western therapeutic approaches, such as client-centred approach, group therapy and family systems approach. It strongly recommends the recognition and use of traditional African dance and music as a supportive therapy, that is, in combination with other forms of therapy, for quality care. Western therapists should be allowed to use traditional African dance and music as a form of therapy since it has been shown that traditional forms of therapy are still highly regarded and utilized among most African people. There should be an interactive and collaborative relationship between traditional healers and western therapists. Accordingly, use of traditional African dance and music could provide a linkage between the two models of counselling.

\section{References}

Akomolafe, A.C. (nd). Decolonising the notion of mental illness and healing in Nigeria, West Africa. Retrieved from http://www.indigenouspsych.org

Buhrmann, M. V. (1981). The Xhosa healers of Southern Africa: Intlombe and Xhentsa - a Xhosa healing ritual. Journal of analytical psychology, 26, 187-201.

Buhrmann, V. (1984). Living in two worlds. Cape Town: Human and Rossouw.

Buhrmann, M. V. (1990). Psyche and soma: Therapeutic considerations. In Saayman, G. S. (ed.). (1990). Modern South Africa in search of a soul: Jungian perspective on the wilderness within. Boston: Sigo Press.

Gladding, S.T. (1997). Community and agency counseling. New Jersey: Merril.

Hammond-Tooke, W.D. (1989). Rituals and Medicines. Johannesburg: A. D. Donker (PTY) LTD.

Henning, S. (2009). Toward a system psychodynamic model of psychological wellness. Retrieved from http;//www.thesis_henning_s.pdf.

Karou, M. (2000). Rhythm and Dance: A Rhythm Journey Movement Experience. [On-line]. Retrived from http://www.africanpercussion.com/healing: Journey/_Dance/_dance.html. [2001, November 22].

Leseho and Maxwell, (2010). Coming Alive: creative movement as a personal coping strategy on the path to healing and growth. British Journal of Guidance and Counseling. 38 (1) 17-30.

Louw, D.A. \& Edwards, D.J.A. (1999). Psychology: An introduction for students in Southern Africa. $2^{\text {nd }}$ edition. Johannesburg: Heinemann.

Monteiro, N. M. and Wall, D. J. (2011). African Dance as Healing Modality Throughout the Diaspora: The Use of Ritual and Movement to Work Through Trauma. The Journal of Pan African Studies, 4(6)234- 252.

Nxumalo, N., Alabe, O., Harris, B., Chersich, M., \& Goudge, J. (2011). Utilisation of traditional healing in South Africa and costs to patients: Findings from a National Household Survey. Journal of Public Health Policy. 32, 124- 136.

Sandlana, N.S. (2002). The use of traditional African dance and music as a therapeutic technique. Unpublished M.A. Thesis, Alice: Department of Psychology, Fort Hare University.

Sandlana, N.S. and Mthethwa, D. (2008). The role of African traditional and religious faith healing practices in the provision of psychlogical wellbeing. Indilinga, 7(2).

Shizha, E. and Charema, J. (2011). Health and wellness in South Africa: Incorporating indigenous and western healing practices. 
International Journal of Psychology and Counseling, 3(9), pp 167-175. DOI: 10.5817/IJPC10.030

Soai, M. (2012). Medical practitioners vs traditional healers: Implications for HIV/AIDS policy. Retrieved from http://www.consultancyafrica.com.

Thornton, R. (2009). The transmission of knowledge in South African traditional healing. Africa: The journal of the international African Institute, 79(1).

Vontress, C.E. (1999). Interview with a Traditional African Healer. Journal of Mental Health Counselling, 21(4), 326. Available: Academic Search Premier. Retrived from http://search.epnet.com.

Zoja, L. (2000). Drugs, addiction and initiation: The modern search for ritual. Romano, M. E. and Mercurio, R. (trans.). Canada: Daimon. 